\title{
Dinâmicas de representações espaciais e dados cartográficos em Lyon no início do século XX: uma primeira abordagem
}

\author{
[ Spatial representations dynamics and cartographic data in \\ Lyon in the early twentieth century: a first approach
}

\section{Enali De Biaggi ${ }^{x}$}

RESUMO - O mapeamento da cidade de Lyon no início do século XX parece ter sido pouco estudado quando comparado ao número de textos dedicados a mapas e cartógrafos do século XIX. Cartografia relacionada com a gestão urbana ou mapeamento militar, vários conjuntos de mapas concentram recursos valiosos para compreender as transformações da cidade naquele momento. Este texto concentra-se em dois pontos principais que parecem emergir: o fortalecimento de um mapeamento detalhado - em escalas de I:500 a I:2.000; e um mapeamento "estendido" no momento em que a cidade se amplia num processo de metropolização. Analisando as continuidades e descontinuidades nos mapas produzidos no período, que vai até ao final da Segunda Guerra Mundial, tenta-se propor novas linhas de pesquisa. -PALAVRAS-CHAVE - Cartografia; mapeamento urbano; Lyon; século XX; metropolização. •

\begin{abstract}
The mapping of the city of Lyons in the early twentieth century has not deserved enough attention compared to the number of texts dedicated to maps and mapmakers of the nineteenth century. From the cartography related to the urban administration to military mapping, several collections constitute valuable resources to understand the changes in the city throughout this period and deserve more attention. This paper focuses on two main issues that seem to emerge: the strengthening of a detailed mapping - I:500 to I:2000 as well as an "extended" cartography which depicts the city in the midst of metropolization. It proposes to analyze continuities and ruptures in the maps produced up to the end of Second World War, trying to suggest new lines of research - KEYWORDS - Cartography; urban mapping; Lyons; XXth century; metropolization.
\end{abstract}

Recebido em 5 de abril de 2016

Aprovado em 25 de julho de 2016

DE BIAGGI, Enali. Dinâmicas de representações espaciais e dados cartográficos em Lyon no início do século XX: uma primeira abordagem. Revista do Instituto de Estudos Brasileiros, Brasil, n. 64 , p. 75-98, ago. 2016.

DOI: http://dx.doi.org/Io.II6o6/issn.23I6-90IX.voi64p75-98

I Université Jean Moulin Lyon 3 (Lyon, França). 
A melhor tradição de análise da história diz que o tempo é um constante fluir de continuidades e rupturas e cujos padrões e conteúdos buscamos captar (ou construir) com a ação do intelecto. Compreender a especificidade de uma época implica desvendar tanto as permanências quanto as particularidades que a singularizam² ${ }^{2}$.

O mapeamento da cidade de Lyon no início do século XX parece ainda pouco estudado quando comparado com o número de textos dedicados a mapas e cartógrafos do século XIX. Nos livros dedicados à análise do mapeamento de Lyon, como Forma Urbis , de fato, a ênfase é no "elogio" dos tempos de expansão da cidade no século XIX (Cadastro de I830, mapas de Dignoscyo - pai e filho, trabalho de Coillet), sendo que pouca atenção é dada ao que ainda foi um momento decisivo na construção da Lyon "moderna".

Este texto tem como objetivo analisar o mapeamento da primeira metade do século XX, dando atenção às continuidades, bem como às rupturas desde o século anterior, com o intuito de destacar as representações espaciais feitas no contexto de metropolização. Usando principalmente os documentos agora disponíveis ao público em geral4, seja o mapeamento relacionado com a gestão urbana ou o mapeamento militar, propomos uma primeira abordagem dos mapas produzidos entre o final do século XIX e especialmente no período que antecede o final da Segunda Guerra Mundial, tentando sugerir linhas de pesquisa para o futuro.

2 MORAES, A. C. R. Geografia histórica do Brasil: cinco ensaios, uma proposta e uma crítica. São Paulo: Annablume, 2009.

3 FORMA URBIS, les plans généraux de Lyon XVIe-XXe siècles. Lyon: Archives Municipales. Les dossiers des Archives Municipales, Archives municipales, 2e édition revue, corrigée et augmentée, I999. Disponível em: $\langle$ http://www.archives-lyon.fr/static/archives/contenu/sommaires/forma_urbis.html〉. Acesso em: 20 jun. 2016.

4 Existem centenas de mapas disponíveis online atualmente. Neste texto nos apoiamos principalmente nos arquivos online do Arquivo Municipal de Lyon (Archives Municipales de Lyon), que serão citados pela sigla AML (〈http://www.archives-lyon.fr/archives/sections/fr/archives_en_ligne〉), mas também no portal do IGN - Instituto geográfico francês (<www.geoportail.gouv.fr〉) E no site da BNF - Biblioteca Nacional da França (<http://gallica.bnf.fr >). 


\section{UM ESFORÇO DE MAPEAMENTO EM GRANDE ESCALA: ESCALAS E DESCONTINUIDADES}

Como em muitas cidades da Europa5, vemos aparecer em Lyon durante todo o século XIX várias tentativas para produzir um conjunto cartográfico capaz de viabilizar a gestão de uma cidade cada vez mais ampla e complexa. Os mapas contribuem, assim, como um instrumento de política pública, a fim de criar um "dispositivo técnico que permita uma concepção concreta da relação política/sociedade, utilizado como elemento de regulamentação de projetos", o qual seria importante analisar.

Em Lyon, um projeto muito ambicioso de mapeamento em grande escala é lançado especialmente a partir do Segundo Império francês (I852-I870)7 e contribui para a afirmação dos novos serviços municipais recém-instalados ${ }^{8}$. Assim, após o esforço de mapeamento do período do cadastro de Napoleão (I824-I832) ${ }^{9}$, na segunda metade do século XIX, são lançadas localmente as bases para a realização de uma cartografia de detalhe: além da finalização e homogeneização de uma nova triangulação geral da cidade de Lyon, iniciada por Fouque entre I86I-I869 e continuada por Grisard a partir

5 Pode-se citar aqui o projeto "Atlas des quartiers de Paris" feito por Vasserot e Bellanger na primeira metade do século XIX descrito por: SOUCHON, C. Philibert Vasserot et les Atlas des quartiers de Paris. CFC, n. I7I, mars 2002, p. 37-4I. Disponível em: 〈http://www.lecfc.fr/new/articles/I7I-article-4.pdf〉. Acesso em: 20 jun. 20I6; o livro de B. P. Hindle sobre os planos de cidades na Inglaterra (HINDLE, B. P. Maps for historians. Chichester: Philimore, I998); bem como a discussão das escalas pertinentes para a cartografia das cidades inglesas relatada por: SEYMOUR, W. A. (Ed.). A history of the ordnance survey. Folkestones WM Dawson \& Sons, I980. Disponível em: 〈https://www.ordnancesurvey.co.uk/docs/ebooks/history-ordnance-survey.pdf〉. Acesso em: 20 jun. 20I6; BARBER, P. London, a history in maps. London: The London topographical society, 2012 (com o detalhe para Londres).

6 LASCOUMES, P. Gouverner par les cartes. Genèses, 3 n. 68, 2007, p. 2-3. Disponível em: <http://www.cairn.info/ revue-geneses-2007-3-page-2.htm >. Acesso em: 20 jun. 20I6. p. 2.

7 GAUTHIEZ B. La transformation de Lyon et Paris au Second-Empire: le projet du ministre de l'Intérieur De Persigny, les exécutants Haussmann et Vaïsse. In: CASAMENTO, Aldo (Dir.). Fondazioni urbane europee dal medioevo al Novecento. Rome: Edizioni Kappa, 20I2, p. 323-344. Disponível em: <http://www.univ-lyon3.fr/latransformation-de-lyon-et-paris-au-second-empire-un-projet-commun-decide-au-plus-haut-niveau--6270I2. kjsp?RH=I347885077I67>. Acesso em: 20 jun. 20I6. O texto faz uma análise detalhada da ação pública em termos de planejamento urbano dessa época, particularmente no que diz respeito ao caso de Lyon, com uma forte intervenção do poder central de Paris, mesmo se localmente o processo decline de maneira específica.

8 Ver a esse respeito a citação de Chinal sobre uma "Notice historique sur les plans de la ville de Lyon", ms., s.d. [ca 1894], redigida pelo serviço viário municipal, para ser apresentada na exposição internacional de Lyon em I894 - caixa AML 938 WP. CHINAL M. Le grand plan parcellaire ou de détails de la ville de Lyon, I860-I970: la contribution des géomètres privés. Forma urbis, les plans généraux de Lyon, XVIe-XXe siècles. Lyon: Archives municipales (Les Dossiers des Archives Municipales n. I0), I997, p. I2I-I34

9 Sobre o cadastro de Napoleão em Lyon, o texto de Gauthiez propõe uma análise detalhada dos métodos e conteúdos a ele relacionados. GAUTHIEZ, B. Lyon en I824-32: un plan de la ville sous forme vecteur d'après le cadastre ancien. Géocarrefour [en ligne], v. 83/I, 2008, mis en ligne le I6 février 20I5. Disponível em: <http:// geocarrefour.revues.org/4542>. Acesso em: 28 mar. 20I6. DOI : I0.400o/geocarrefour.4542. 
de I868, serão os topógrafos chamados a trabalhar sob contrato e não os agentes municipais ("voyers") os responsáveis a partir de então pelo "grande levantamento topográfico cadastral da cidade de Lyon” durante IIo anos (I860-I970) ${ }^{\mathrm{IO}}$.

Realizadas pela primeira vez na escala de I:500, as plantas cadastrais são elaboradas paralelamente ao trabalho de triangulação, começando pelas áreas onde o número de pontos geodésicos levantados já seria suficiente. Inicialmente, espera-se criar 342 folhas ou conjuntos de folhas que representam toda a cidade de Lyon daquele momento, cada folha medindo I $\mathrm{m}$ de largura e o,6 $\mathrm{m}$ de comprimento e cobrindo uma área de I5 hectares. Esses mapas, feitos sob comando do Departamento Viário Municipal, favorecem a representação de "objetos urbanos", tais como calçadas, fontes, lustres, quiosques, bancos, mas também mostram os projetos de desenvolvimento planejados, que gradualmente acabam mudando os traçados de ruas e edifícios. Pode-se assim ver a chegada e o desaparecimento dos trilhos de bonde, bem como novos projetos de construção ou alinhamentos, por vezes nem levados a cabo, mas visíveis em traçados em sobrecarga sobre as plantas disponíveis. Os edifícios aparecem com os seus números nas vias públicas e, dependendo do período, o nome de seus proprietários. Atualmente disponíveis no site dos Arquivos Municipais de Lyon, é fácil ver a evolução das diferentes edições produzidas ao longo do tempo, atingindo um total de 604 plantas, para a cobertura total da cidade (2.479 mapas na série 4S dos Arquivos Municipais de Lyon) ${ }^{\mathrm{II}}$ : em I863 aparecem as primeiras edições ainda manuscritas, onde a assinatura do responsável está presente. Em seguida, as atualizações vão ocorrendo em momentos diferentes para cada folha, criando uma média de 4 a 5 edições por folha até I980. Esse acervo é um recurso importante para quem pretende estudar as transformações da área urbana de Lyon, mesmo que o ritmo de produção de plantas esteja longe de ser uniforme ou regular para todo o território (gráfico I).

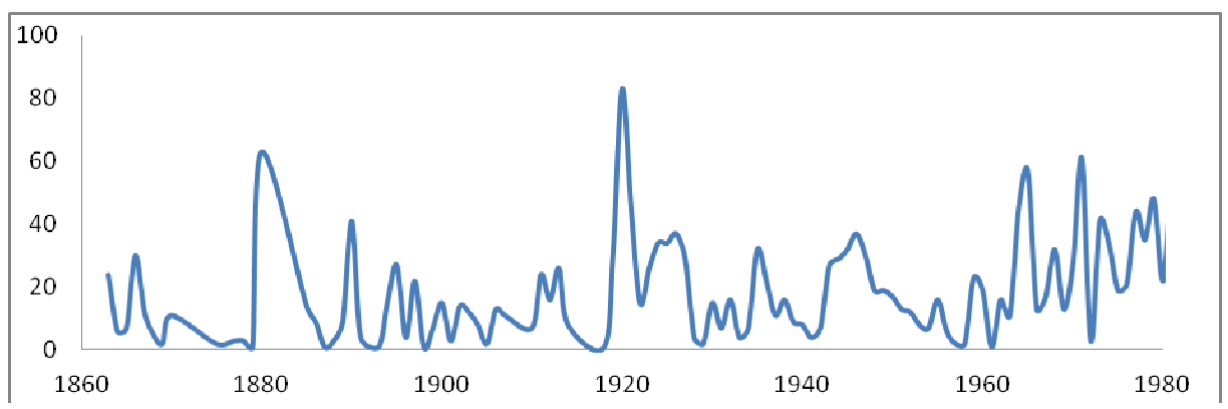

Gráfico I - Frequência de publicação das plantas I:500 entre I863I98I - série 4S AML. Elaborado por DE BIAGGI, 2015

Io CHINAL, M. Le grand plan parcellaire ou de détails de la ville de Lyon, I860-I970: la contribution des géomètres privés. Forma urbis, les plans généraux de Lyon, XVIe-XXe siècles. Lyon: Archives municipales (Les Dossiers des Archives Municipales n. I0), I997, p. I2I-I34. Disponível em: <http://www.archives-lyon.fr/static/ archives/contenu/sommaires/forma_urbis.html >. Acesso em: 20 jun. $20 I 6$.

II Série de plantas 4S, acessíveis no site: Archives Municipales de Lyon (<http://www.archives-lyon.fr/archives/ sections/fr/archives_en_ligne/le_territoire/cartes_et_plans $>$ ). 
Uma primeira análise dos autores e datas de publicação demonstra a existência de diferentes "ondas" de publicação e uma distribuição bastante lógica das áreas da cidade: uma grande parte da cidade antiga (centro e oeste de Lyon, com o distrito de Vaise) é confiada, primeiro, a Balthazard Vignat, que produz III folhas entre I863-I876, no momento do lançamento do projeto ${ }^{\mathrm{I2}}$; a margem esquerda do rio Rhône ${ }^{\mathrm{I3}}$ é compartilhada entre E. Simon (Io folhas criada em I869), G. Mermet ( 45 plantas em I878-I879 e I905-I9I2), mais tarde associado a A. Vernay para produzir 98 folhas entre I885 e I896. Se G. Mermet garante a continuidade na passagem de um século para outro, num momento em que o ritmo de publicação parece diminuir, no século XX outros nomes estão associados a esse levantamento sistemático, especialmente Joanny Guillermain ${ }^{\mathrm{I}}$, que atinge 88 plantas feitas entre I9I3-I926 e garante uma recuperação significativa, visível logo após a Primeira Guerra Mundial. Os outros topógrafos envolvidos, como, por exemplo, Georges Berthier (responsável por 23 folhas entre I965-I969), o gabinete Perraud (4 em I966), Jean-Claude Sorro (uma planta em I970) e, finalmente, Roger Arnaud (uma folha em I970) vêm completar a coleção na segunda metade do século XX, ressaltando-se principalmente durante a recuperação da produção que ocorre após a Segunda Guerra Mundial (figura I).

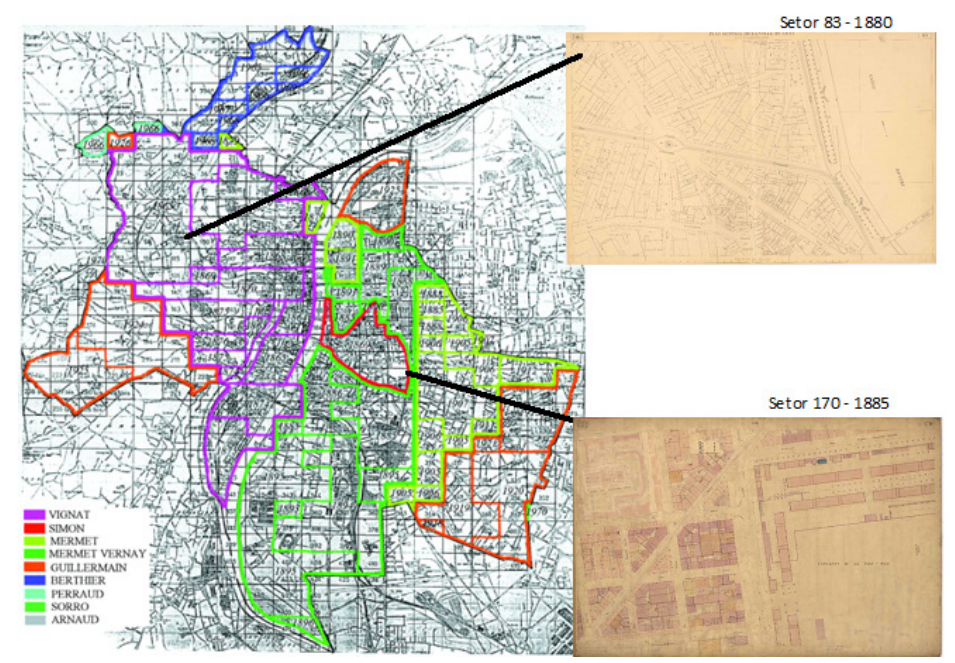

Figura I - Distribuição das áreas da cidade entre os topógrafos para a realização da cobertura I:500 de Lyon como apresentada em Forma Urbis (I995) - dois exemplos de folhas

I2 Em Chinal são indicadas as dificuldades para a realização contínua das plantas de B. Vignat, seja pela espera dos cálculos de triangulação, pelas disputas sobre o conteúdo das plantas e sobretudo pelas mudanças na administração devido à troca de regime político (do Império à $3^{\mathrm{a}}$ república), especialmente em I87o, resultando na demissão do principal engenheiro em chefe do serviço viário, G. Bonnet, no cargo desde 1854. CHINAL, M., op. cit. I3 Apesar de a tradução do rio Rhône existir como Ródano, preferimos guardar o nome em francês neste texto para marcar a correspondência entre o nome do rio e da unidade administrativa superior ao nível municipal (commune) na França, que é o departamento (Département). Sobretudo no período de estudo, o responsável pelo departamento, o "préfet", também intervinha no nível municipal.

I4 J. Guillermain também foi formado por Mermet, o que garante ainda uma vez a continuidade do projeto. 
Se a criação da planta é dada sempre ao mesmo topógrafo, muitas vezes pago a preço fixo, tanto por ponto de triangulação como para o desenho do plano por hectare (entre 30 e Ioo francos por hectare), a revisão e a criação do material de edição podem ser dadas a diferentes profissionais, cujos nomes são indicados nos cadernos de anotações que acompanham as folhas ${ }^{\mathrm{I5}}$, a um preço bem menor por hectare. A reprodução é feita primeiramente pela técnica de litografia e em seguida por autografia em Lyon.

A partir de I887 as plantas I:500 servirão como base para um novo projeto de mapeamento da cidade a I:2.000 ${ }^{\mathrm{I} 6}$ por meio de redução. As primeiras plantas de I:2.000 aparecem a partir de I9Io e dizem respeito principalmente às regiões do município sujeitas à revisão dos limites: a oeste, a fronteira entre Lyon e a cidade de Tassin-la-Demi-lune e, a leste, os limites com Villeurbanne. A maior parte das 32 folhas em I:2.000, obtidas a partir da redução por pantógrafo de I6 setores originais feitos em I:500, foram editadas juntas no final da Primeira Guerra Mundial, em I920 (edição de 28 folhas). Somente no ano de 1984 se ultrapassa esse "feito" com uma única folha, sem ter uma edição contemporânea. Esse fato é importante ao se considerarem os melhores momentos para realizar uma base cartográfica homogênea a partir dessa série de mapas.

Essa nova série, produzida primeiro em cores, no início dos anos de I920, rapidamente retoma a aparência de mapas topográficos em preto e branco, feitas em I:500, indicando os nomes e números de ruas, mas citando apenas os nomes das principais instituições públicas e religiosas. Da mesma forma que a série I:500, o mapeamento I:2.000 será relançado várias vezes (entre 3 e, às vezes, até I2 vezes, caso da folha I4 - ver gráfico 2). Pelo ritmo da edição, pode-se imaginar que eles são valorizados de modo especial na segunda metade do século XX, quando mais da metade das plantas existentes foram editadas, o que demonstra sua importância para a gestão municipal (figura 2).

I5 Os "cahiers des états indicatifs" - cadernos de anotações referentes a cada folha - encontram-se parcialmente disponíveis (473 do total de 604 plantas).

I6 Plantas também disponíveis no site: Archives Municipales de Lyon (<http://www.archives-lyon.fr/archives/ sections/fr/archives_en_ligne/le_territoire/cartes_et_plans $>$ ), série 5S AML. 


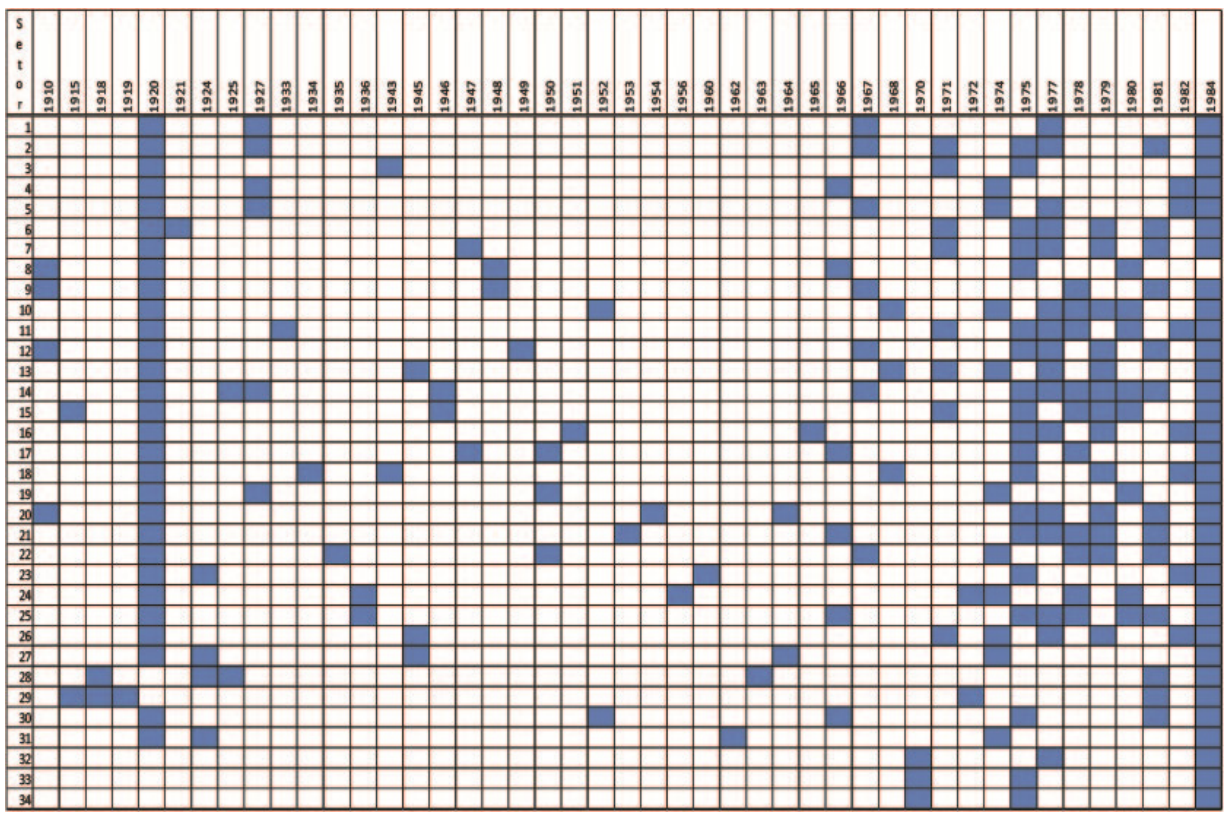

Gráfico 2 - Ritmo de publicação das plantas 1:2.00o por setor

$-5 \mathrm{~S}$ série AML. Elaborado por DE BIAGGI, 2015. 


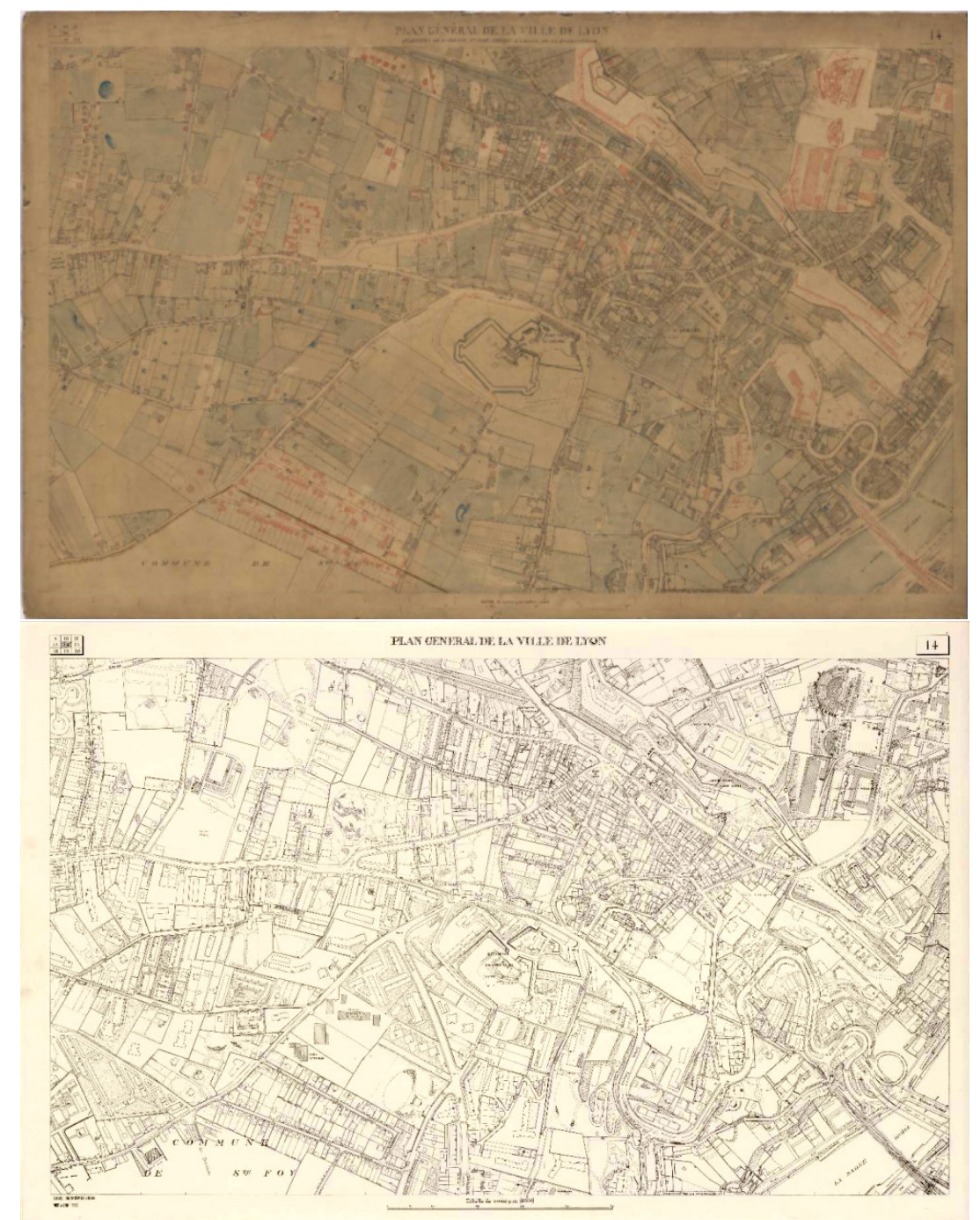

(A)

(B)

Figura 2 - Evolução das plantas I:2.000 AML - Setor I4 em I920 (figura A) e I980 (figura B)

No início do século XX, outra nova série topográfica será tentada: a partir de março de I925, um mapeamento na escala de I:I.000 é confiado a J. Guillermain, já responsável pela revisão total do plano em I:500 (4.500 ha, sem os I30 hectares do Parque Tête d'Or). O estabelecimento das plantas na escala de I:I.ooo, também por técnicas de redução do I:500, foi avaliado como valendo I4 francos por hectare (2 francos a menos que a revisão de I:500) e deveria ser realizado durante quatro anos, mas, depois de vários atrasos e extensões de tempo, o topógrafo se empenhou em terminar I03 folhas até o dia 3I de dezembro de I939! A tentativa de mapeamento em I:I.00o não resultou em uma cobertura geral da cidade, sendo efetivamente realizada para a parte localizada no centro e a leste na cidade (mapa AML 2So543). 
Essa escala não parece ter sido considerada adequada para traduzir as preocupações de planejamento do território do momento, que iam muito além da cidade de Lyon.

\section{DO MAPEAMENTO CIVIL AO MAPEAMENTO MILITAR: ACOMPANHANDO UMA CIDADE QUE ULTRAPASSA OS SEUS LIMITES}

As plantas em grande escala formam a base de outros mapas que serão utilizados pelo município para a gestão de um espaço que continua a crescer durante todo o período. A maior expansão do território de Lyon ocorre em I852, com a anexação de três “faubourgs" I7 (Guillotière, Croix-Rousse e Vaise), extensão seguida em I894 por limites deslocados para o leste na área do Parque da Tête d’Or (nordeste de Lyon), graças ao pagamento da quantia de 25.000 francos para a cidade vizinha de Villeurbanne. Os últimos "ajustes" dos limites da cidade de Lyon ainda ocorrem ao longo do século XX, tanto em I9I3, na parte do território da cidade de Caluire, onde é construído o hospital de isolamento de Croix-Rousse, ou ainda na parte do hospital Debrousse, cujas dependências se localizavam em parte no município de Sainte-Foy-lès-Lyon ${ }^{\mathrm{I}}$. Finalmente, em I963, a cidade de Saint-Rambert-l'Île-Barbe também é anexada a Lyon, o que permite estender o distrito industrial de Vaise a oeste da cidade ${ }^{\text {I9 }}$.

O "transbordamento" da cidade é visível em muitos mapas temáticos disponíveis em arquivos. No final do século XIX, há um primeiro mapa básico preparado na escala de I:I0.000 com a data de referência de I87I, mapa que será usado em ocasiões diferentes para o tratamento de vários temas - o "Mapa oficial de ruas e lugares públicos da cidade de Lyon - feito em I870 pelo engenheiro-chefe do serviço municipal” (figura 3A). Esse mapa de base, com uma legenda em que aparecem monumentos públicos e religiosos, estações ferroviárias, ruas, túneis e linhas de ferrovias, bem como os limites de outorga (para a cidade com os bairros da concessão), é publicado pela litografia do Salut Public (jornal local) e servirá de base para tratamentos temáticos: a indicação dos locais de mastro, jogos, fogos de artifício e regatas em momentos de festa (Mapa 2Soo28a AML), uma indicação de bocas de incêndio, hidrantes, fontes e chafarizes monumentais (2Soo28b AML), ou para várias anotações manuscritas: números da população por distrito (2Soo67a $\mathrm{AML}$ ), terras de propriedade da cidade durante uma revisão de escolas primárias existentes (2SoI50 AML), estatísticas de nascimentos por paróquia em Lyon (2SoI72 AML). Em alguns desses mapas “comuns”, já vemos a necessidade de ir além da área

I7 Como em Paris, a anexação de cidades vizinhas é feita por decreto presidencial em I852, pouco antes da chegada do novo prefeito, Claude-Marius Vaïsse, nomeado também pelo governo central de Paris.

I8 Essas cessões foram feitas em troca do direito à utilização dos ditos hospitais. Ver: VANARIO, Maurice. Lyon, du XVe siècle à nos jours: l'évolution de la ville à travers les principaux plans. Forma urbis, les plans généraux de Lyon, XVIe-XXe siècles. Lyon: Archives Municipales (Les Dossiers des Archives Municipales n. Io), I997, p. I2I-I34. Disponível em: 〈http://www.archives-lyon.fr/static/archives/contenu/sommaires/forma_urbis.html〉. Acesso em: 20 jun. 2016.

I9 Ver a indicação detalhada das diferentes leis e decretos que permitiram a evolução das fronteiras da cidade em: VANARIO, Maurice, op. cit. 
de abrangência inicial, que chegava até a linha de fortificações ao leste da cidade. De fato, no mapa correspondente às especificações para a recolha e eliminação de lixo (“imundices"), onde são propostas as rodadas de limpeza para o período de I883-I887 (2So223 AML), as ruas e estradas departamentais são estendidas para além do quadro e se sobrepõem ao título do mapa. Em I887, durante a criação de uma rede de telefones para o serviço de bombeiros, chega-se mesmo a colar uma folha extra para a parte sudeste da cidade para acomodar as zonas integradas aos planos gerais da cidade (AML 2So460 - figura 3B).

A)

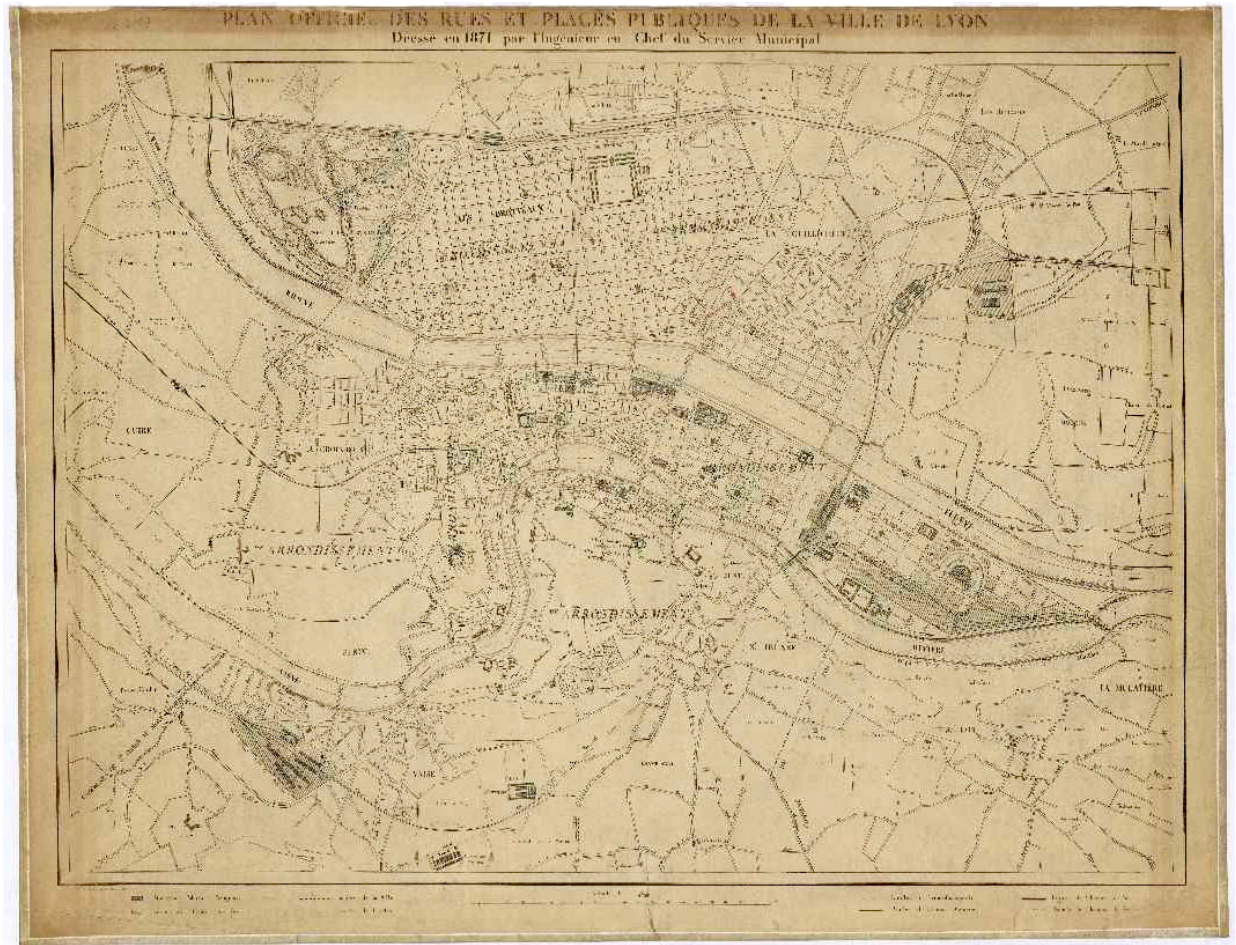

Mapa AML 2S0067, 1871 
B)

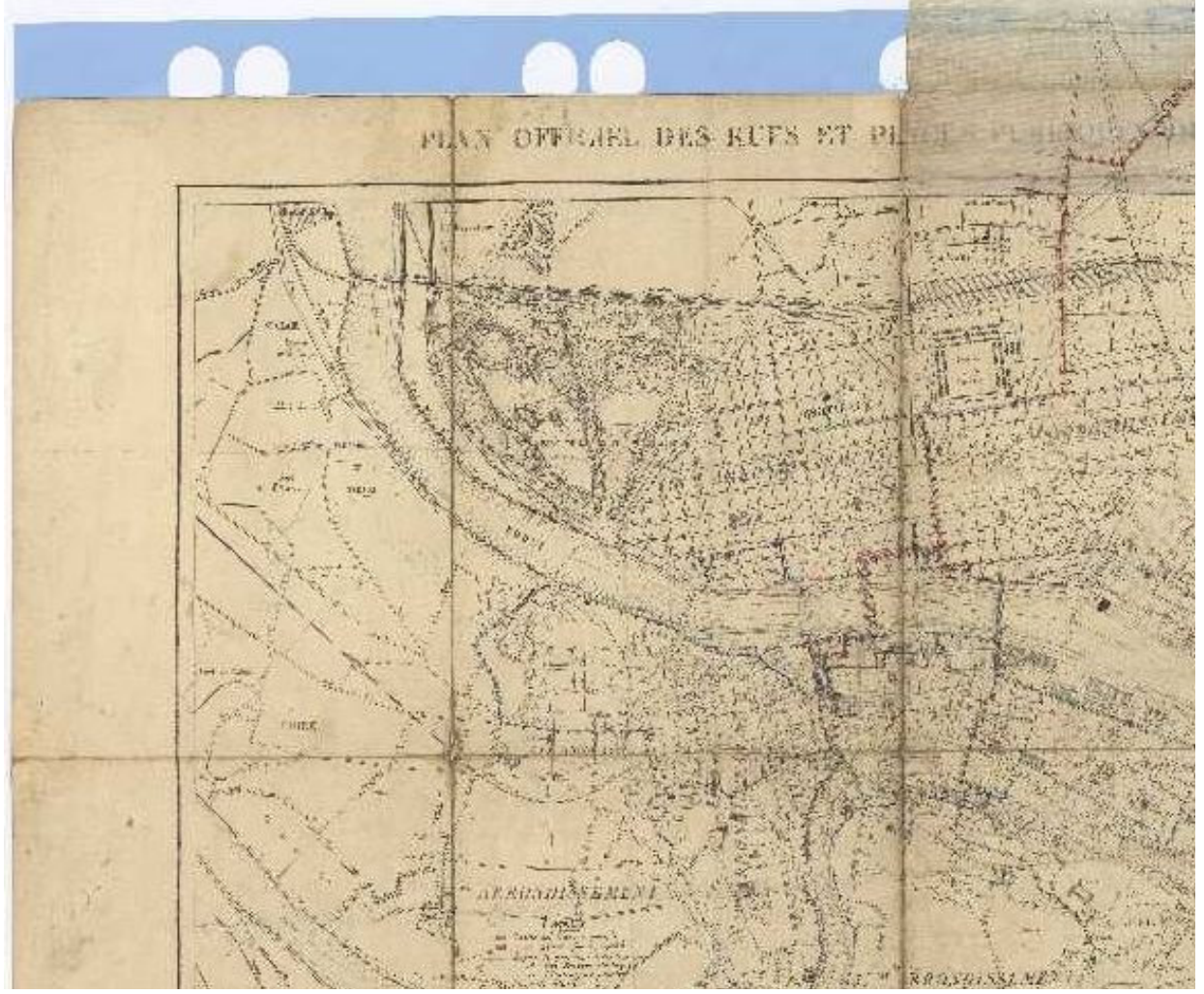

Mapa AML 2S0460, 1887

Figura 3-O mapa de base original (A) - AML 2Soo67 -, feito em I87I para a gestão municipal, incapaz de conter todos os elementos necessários para o planejamento dos serviços municipais no exemplo da rede telefônica (B) - Mapa AML 2So460, I887 
O serviço vicinal, em nível departamental do Rhône, já no final de I86o, começa a usar outro mapa expandido como base para o mapeamento destinado a abordar temas que necessitam de melhor integração dos municípios vizinhos a Lyon. O "Plano geral para a cidade de Lyon" também é composto na escala de I:Io.000 ${ }^{20}$ e corresponde a uma série de mapas que também contêm, em muitos casos, a influência dos engenheiros da cidade ${ }^{2 \mathrm{I}}$ (cujas assinaturas constam no verso). Os elos entre esses novos mapas, feitos em I:Io.0oo e orientados ao norte, com os mapas da cidade mostrados anteriormente (figura 3), cuja orientação é a leste, tornam-se visíveis quando se procede à análise de detalhe. Na região no interior da linha de fortificações, o desenho é bastante similar, ao contrário do que se encontra no exterior dessa linha, cujo traçado parece indicar outras fontes. A montagem torna-se evidente nesses novos mapas quando observamos os topônimos exibindo diferentes orientações $^{22}$ (figura 4).

\footnotetext{
20 Ver exemplares na série IS - catalogados na classe de grande tamanho em ambos os arquivos municipais, o de Lyon e o departamental do Rhône.

2I Só mencionamos aqui aqueles que serviram durante um período que lhes permitiu realizar projetos de longo prazo, tais como G. Bonnet para o período I854-I870, e Camille Chalumeau para o período I9IO-I945, mas outros funcionários do Conselho municipal também deixaram certamente suas marcas sobre a cidade.

22 Ver a esse respeito os mapas AML ISoo8a et ISoo8b de I90o onde justamente a extensão da cidade foi projetada. Disponível em: <http://www.fondsenligne.archives-lyon.fr/ark:/I88II/eb906b5a2ocab63f23db8 3def688Ibbd>.
} 


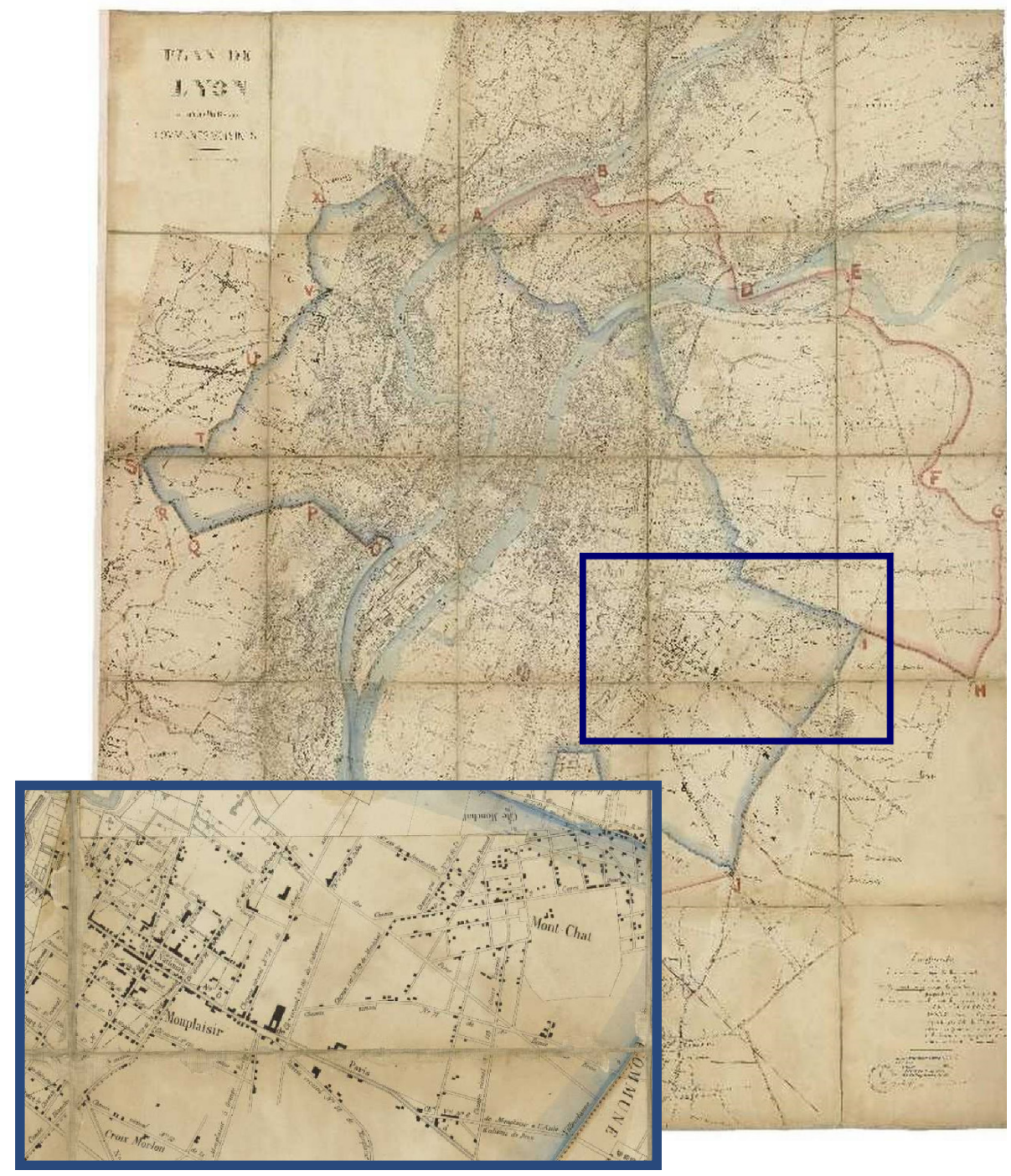

Figura 4-Um dos primeiros mapas do serviço vicinal departamental do Rhône, de I874, cujos detalhes indicam várias lógicas de criação, visíveis na direção dos topônimos e também nos modos de representação (AML ISoo2)

A integração de mapeamentos diferentes parece se aperfeiçoar no momento em que a discussão dos perímetros de outorga intervêm. A série de mapas que datam de I890 a I892, feitos com base no plano de I874, mostra como se impõe, no final do século XIX, a questão de considerar uma superfície "aglomerada" que ultrapassa os antigos limites, especialmente no leste da cidade (no $3^{\circ}$ e $6^{\circ}$ distritos). Isso implica o movimento de barreiras que delimitam a área de tributação da cidade, o rearranjo dos 
serviços militares e de escritórios e postos de controle, como proposto pela Comissão Municipal nos mapas AML IS005 até ISo05f, especialmente IS005c, de I892. Esses mapas integram, de fato, um outro projeto de mapeamento do território francês, ligado à engenharia militar, já que no final do século XIX o mapeamento nacional francês ainda é uma responsabilidade militar, tendo no SGA (Serviço Geográfico do Exército) o bastião das tradições topográficas. Os mapas produzidos pelas brigadas topográficas do "Génie", feitos para Lyon graças a levantamentos efetuados entre I880 e I88I (figura 5), parecem muito com a representação das áreas vizinhas à cidade vista na figura 4, como mostrados nos mapas do departamento de Rhône.

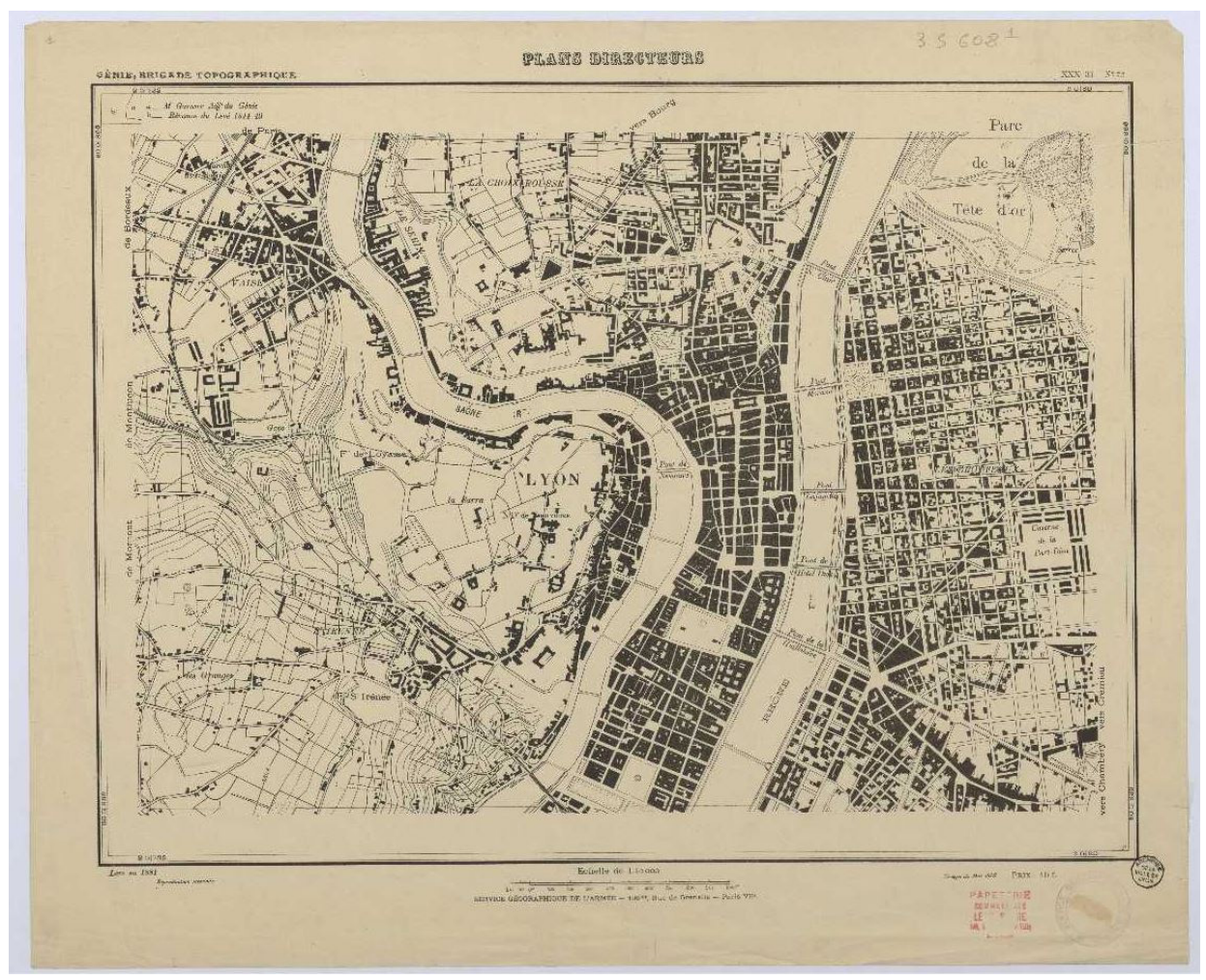

Figura 5 - Mapa do Plano Diretor de Lyon publicado pelo SGA Serviço Geográfico do Exército (AML 3So608), I880

Os Planos Diretores feitos na escala de I:Io.000, bem como os mapas da série conhecida como "tipo I922", realizados em I:20.000 e I:50.000, apoiam-se na rede geodésica nacional francesa (NTF) e terão distribuição limitada, sofrendo atualizações irregulares ao longo da primeira metade do século XX. Somente com a chegada do IGN - Instituto Geográfico Nacional, de responsabilidade civil a partir de I940, e, sobretudo, com o final da Segunda Guerra Mundial, a difusão e o ritmo de produção de mapas topográficos nacionais se transformam, auxiliados igualmente pela chegada de levantamentos aerofotogramétricos generalizados, que dão novo 
impulso à representação cartográfica. Nesse início do século XX, no entanto, são os mapas de I880 e I88I que serão reutilizados continuamente, completados por um uso aparentemente pontual das novas técnicas de levantamentos aerofotogramétricos que surgem e se aperfeiçoam. Um dos primeiros levantamentos fotogramétricos disponíveis para a região data de I920, mas abrange somente a área onde se pretende construir o novo porto de Lyon, no sul da cidade (figura 6). As outras campanhas disponíveis para o início de século XX afetam pequenas áreas da cidade ou seus arredores, onde transformações especiais estavam em andamento ${ }^{23}$. A campanha de I938, realizada em agosto na escala de I:20.000, parece ser o único projeto feito para cobrir toda a cidade antes de I945, mas sua utilização precisa ainda ser esclarecida.

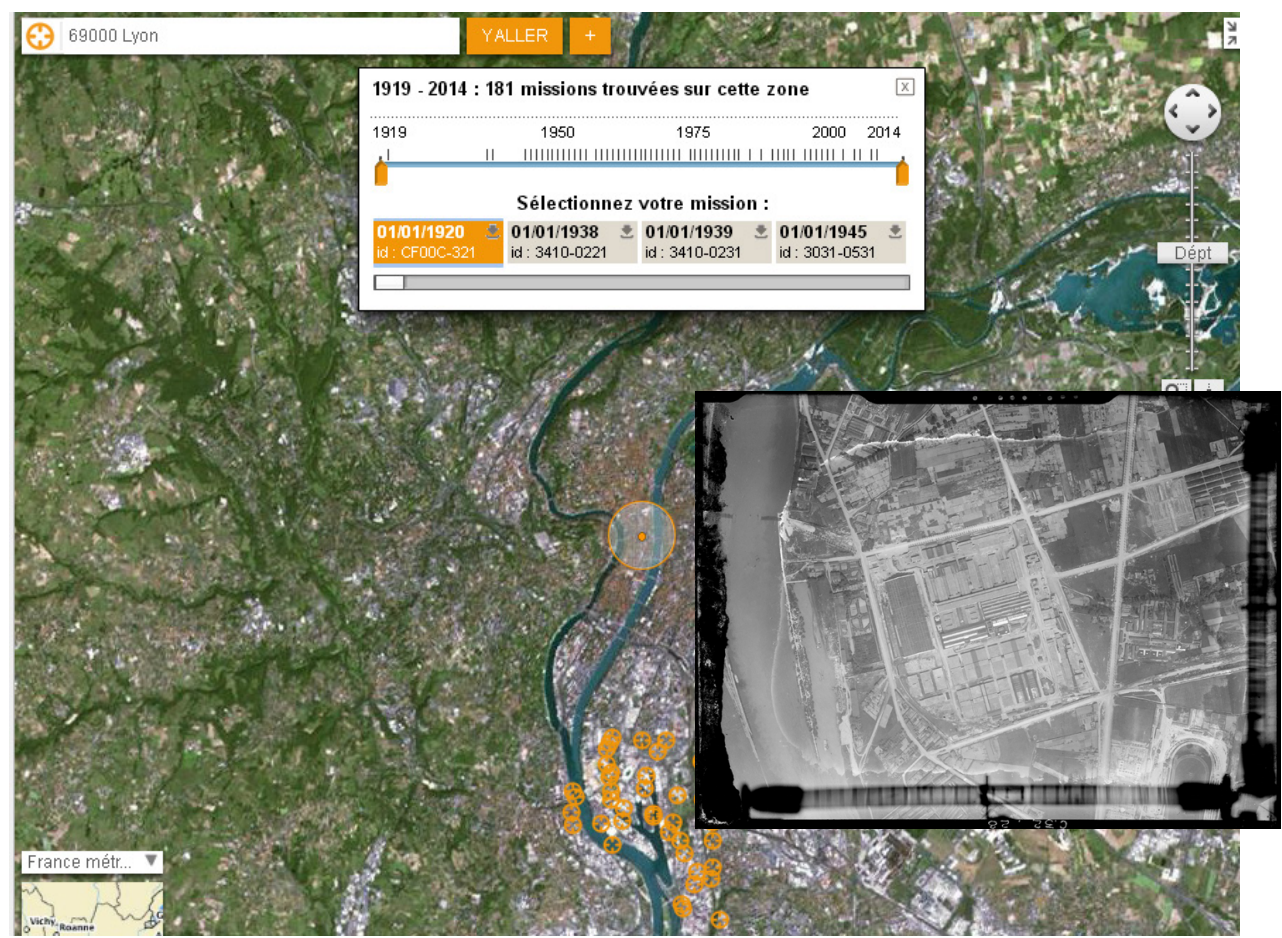

Figura 6 - Primeiras campanhas de fotografias aéreas verticais disponíveis para a região de Lyon - exemplo da campanha de I920 sobre a área onde será construído o novo porto Edouard Herriot, finalmente inaugurado em I938

23 Ver, a esse respeito, as imagens disponíveis em <http://www.geoportail.gouv.fr/accueil〉, no botão "voltar no tempo" (em francês: "remonter le temps"). 


\section{DESENHANDO A METRÓPOLE}

Se a ideia de uma área "metropolitana" parece surgir no discurso político local desde meados do século XIX ${ }^{24}$, quando se representa Lyon nos séculos XVIII e XIX, os mapas e plantas focam especialmente a região situada entre os dois rios que, de certa forma, delimitam o centro da cidade: o Rhône e o Saône. Na maioria das vezes, a cidade é representada com a orientação a oeste, em direção à colina de Fourvière, local de instalação antiga. Quando a cidade é representada de maneira "pitoresca" no final do século XIX ${ }^{25}$, é essa a orientação que parece mais apta para dar uma impressão capaz de mostrar a grandeza dos monumentos da cidade.

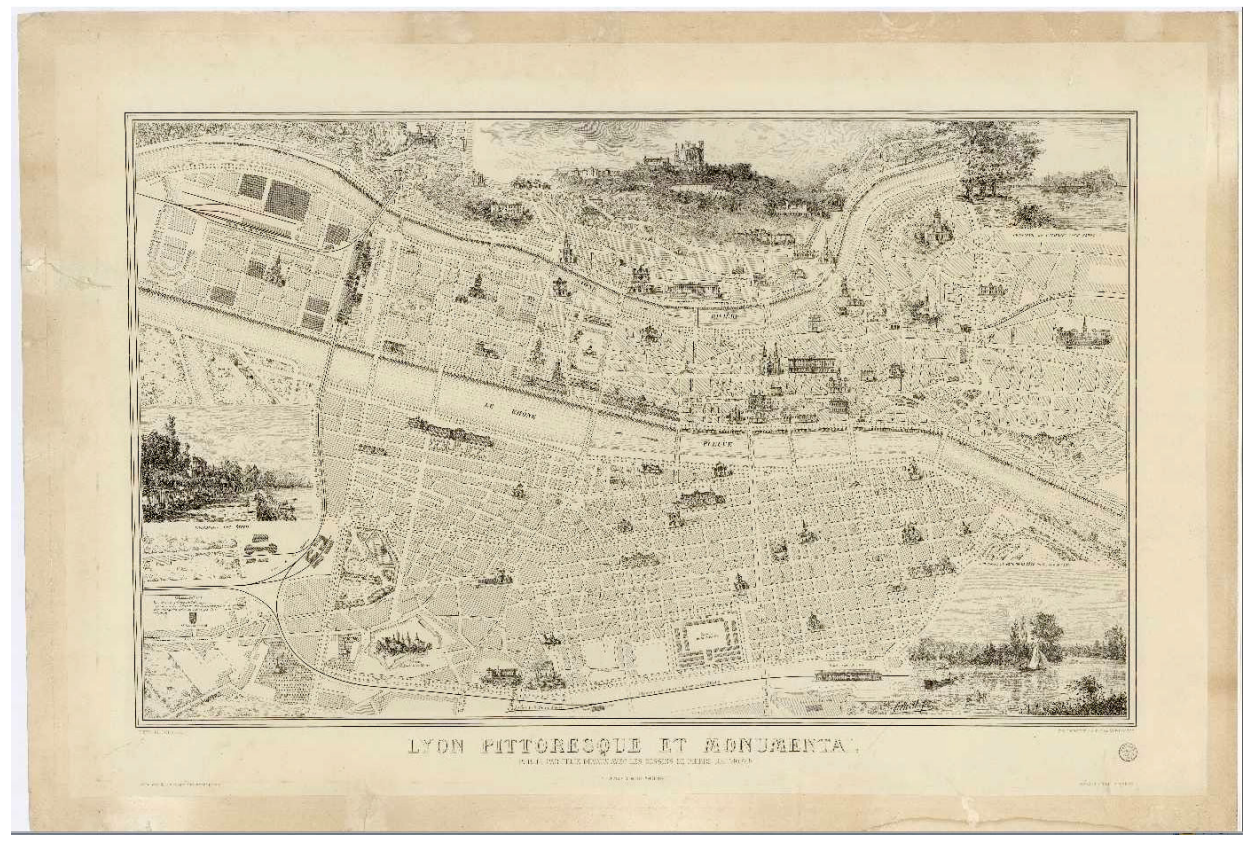

Figura 7-Um dos vários mapas "pitorescos e monumentais" de Lyon, do final do século XIX, de P. Reithofer, AML 2S0333

No entanto, nos planos do serviço municipal da cidade da segunda metade do século XIX, é a orientação a leste que predomina, região de expansão da cidade para além de uma primeira zona de fortificações construídas em I830 e revistas em I870.

24 Ver citação em: GAUTHIEZ, B., op. cit., 20I2, p. 325.

25 Outra tradição da cartografia urbana do período. SCHULER, C. J. La ville: la cartographie urbaine de l'Antiquité au XXe siècle. Paris: Place des Victoires, 200I. Ver, no caso de Lyon, "Lyon pittoresque et monumental" de I89I, de P. Reithofer (AML 2SI292). 
Os dois cartógrafos Dignoscyo, pai e filho, bem como J. Rembielinski ${ }^{26}$ começam a propor a orientação para o leste a partir de I860, e os mapas de base do serviço viário municipal, publicados em I870 e mencionados anteriormente (figura 3), mostram a mesma orientação. No entanto, os Planos Diretores de origem militar, bem como as plantas cadastrais, orientam as folhas ao norte, tradição topográfica que prevalecerá finalmente no início do século XX, ao mesmo tempo que se modifica o centro das representações.

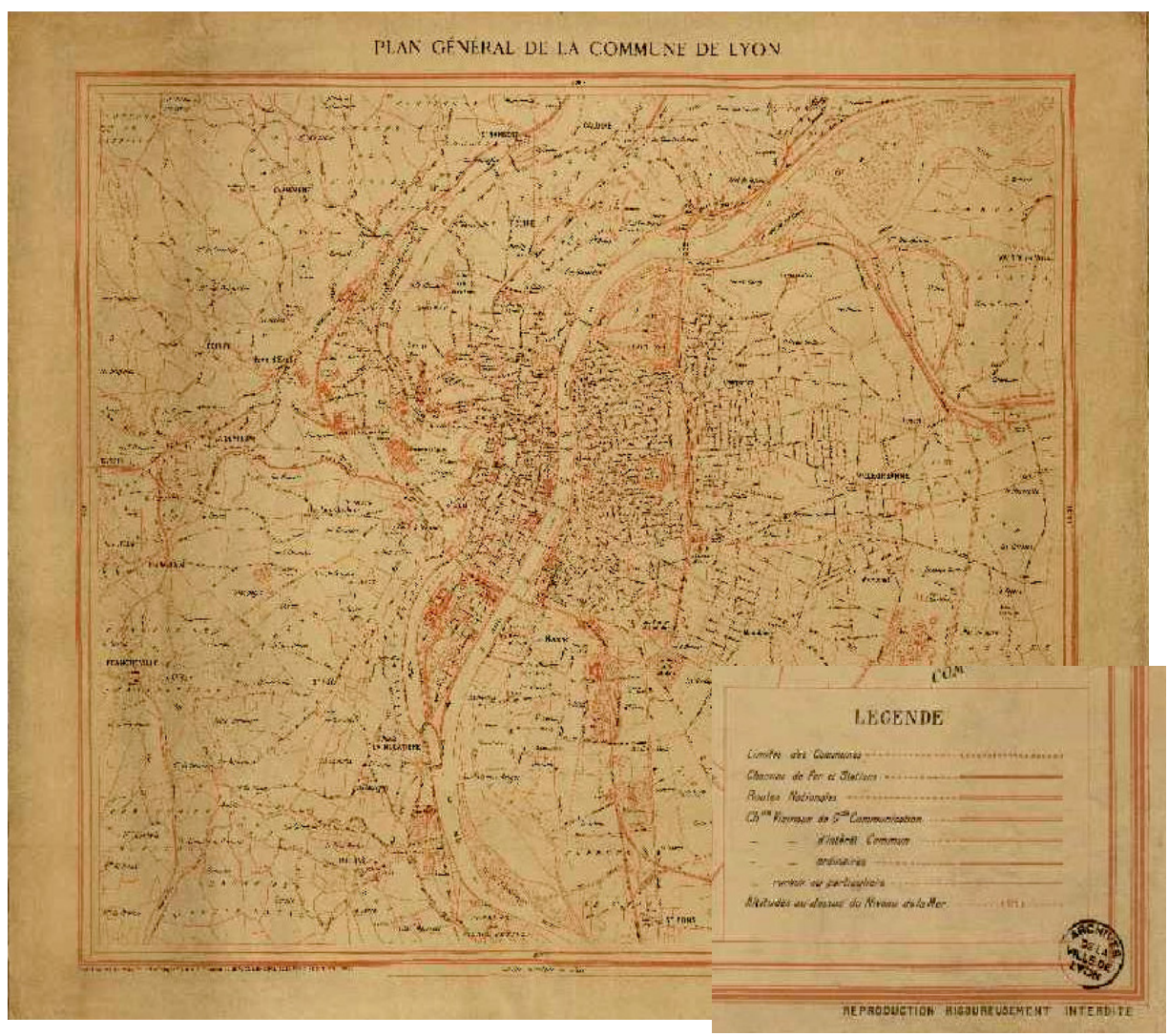

Figura 8 - Plano geral da cidade de Lyon (AML 2SoI64), datado de I908, feito por outro topógrafo, Paul Saint-Denis, responsável por grande parte das publicações cartográficas da cidade de Lyon, no início do século XX. Depois de ter atualizado o mapa da cidade de Lyon publicado pelo Serviço Viário Municipal, ele faz o levantamento do mapa na escala de I:5.000 e também ajuda a mapear o resto do departamento do Rhône, participando, por exemplo, da edição local da série de mapas industriais da França (AML 2S0456)

26 E. Rembielinski, no entanto, oferece desde I855 um "mapa topográfico da cidade de Lyon e do canton de Villeurbanne”, onde estão representadas, além das áreas construídas e dos nomes dos bairros, com elementos manuscritos, duas parcelas de um canal de desvio e uma nova barragem na margem esquerda do Rhône (Mapa AML 3 So279a). 
O Plano geral da cidade de Lyon, datado de I908, feito por Paul Saint-Denis, topógrafo trabalhando para o Serviço Viário Municipal, é um dos primeiros a retomarem a orientação norte para formar um mapa de base. Além de recentralizar a representação da cidade, o mapa inclui Lyon e a cidade vizinha de Villeurbanne a leste: a área entre os dois rios encontra-se um pouco fora do centro, à esquerda, enquanto o vale do Rhône, a leste, parece ganhar em importância (figura 8). Do ponto de vista prático, a rede de bondes instalados em I880 e eletrificados gradualmente a partir de I890 já havia colocado em questão as ligações entre o centro da cidade e sua periferia - os mapas sucessivos mostrando a evolução das linhas deixam entrever a continuação dos transportes fora dos mapas quando estes são focados apenas em Lyon $^{27}$.

No início do século XX, a necessidade de ampliar a visão da cidade para além do centro aparece também sob a forma de um mapa humorístico, publicado em I9Io, sobre a "Lyon moderna". A modernidade que a cidade quer mostrar é o tema da exposição internacional urbana, ali realizada em I9I4, e em todo o mapa aparecem críticas como na legenda: "Aviso importante para o leitor: em Lyon existe uma única rua, a rua da República e a passagem “'Argue”, ou seja, dois elementos localizados no centro da cidade, entre os dois rios, lugar de reunião da população mais rica da cidade (figura 9).

27 Ver especificamente os mapas do projeto das dez primeiras linhas de bondes feito em I880 (AML 3SoI68) e os mapas de transportes de Lyon publicados pelos guias turísticos $\mathrm{POL}$ ( $\mathrm{AML}_{3} \mathrm{SO}_{303}$ ). 


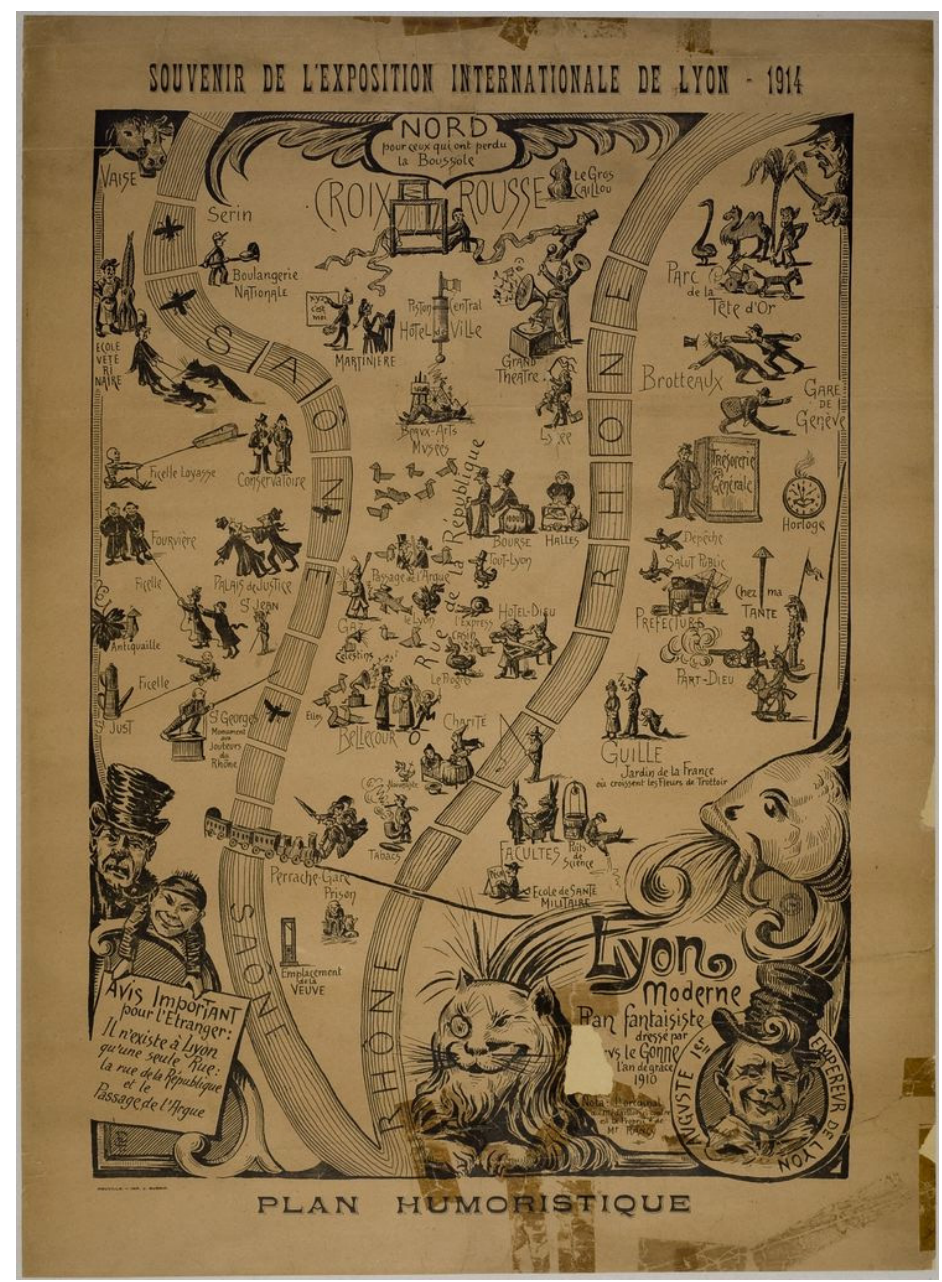

Figura 9-Um dos planos humorísticos publicados por J. Orset em I9Io e I9I4, com vários “mitos” de Lyon (AML 2SIO66)

As questões relativas aos elos entre o centro e a periferia serão o objeto de toda uma outra série de mapas produzidos no início do século XX, tendo como objetivo um novo plano de desenvolvimento da cidade apresentado em I935 - o Plano Chalumeau. No final da Primeira Guerra Mundial, uma nova lei sobre planos de gestão, embelezamento e expansão (I9I9-I924) incentiva os municípios a considerar sua extensão a partir das principais estradas do anel viário, proporcionando acesso a dispositivos diferentes no centro da cidade. Em Lyon, esse projeto aparece mais cedo: já em I9I2 uma comissão extramunicipal, com 70 membros, foi formada para 
"estudar o desenvolvimento de um plano de expansão para a cidade de Lyon"28. Inspirando-se em modelos alemães e helvéticos, o trabalho da comissão de Lyon será prejudicado pelo advento da guerra. No entanto, seu progresso será visível na série de mapas de planejamento manuscritos, feitos nas escalas de I:20.000 a I:50.000, cujos autores serão, entre outros, Camille Chalumeau, engenheiro-chefe da cidade em I9I0-I945, e Eugene Pierre Lapeyre, topógrafo principal, que se esforçam em criar vias de acesso ao centro da cidade (estradas, ferrovias, portos) e uma série de avenidas e túneis capazes de respeitar o fluxo contínuo de tráfego (figura Io).

On s'est efforcé de relier toutes les routes convergentes par une artère formant une ceinture à grand trafic aux portes même de la ville; c'est en effet une solution logique au problème que de relier ainsi les routes radiales par une voie nouvelle formant rocade.

Du côté de la plaine, c'est-à-dire rive gauche du Rhône, ce problème a été relativement facile à résoudre. Le boulevard dit " de ceinture ", dont nous avions proposé la création dès I9I4, à l'emplacement même des murs d'enceinte de la ville, a reçu un commencement d'exécution. [...] Ce boulevard est prévu avec une largeur de 46 mètres, comportant deux chaussées de Io $m 50$ chacune, séparées par un trottoir de I3 mètres avec jardins et plantations. [...] En tenant compte des larges avenues que sont les quais du Rhône, on peut dire que, très prochainement, une circumliaison vraiment intéressante sera réalisée pour toute la partie Est de l'agglomération lyonnaise.

En ce qui concerne le secteur à l'ouest du Rhône, le problème est plus difficile à cause de la topographie locale. [...] En réalité, la liaison des routes du nord, nord-ouest, ouest, et sud-est de Lyon est à réaliser de toutes pièces. La solution à adopter est plus difficile à trouver du fait que le relief du sol ne permet la création de grandes routes droites à l'air libre; les rampes seraient, en effet, excessives. Pour ce secteur, la grande route d'intercommunication devra donc, en grande partie, être établie en tunnel. [...] Le projet du plan d'aménagement et d'extension de Lyon que nous avons établi comporte ainsi deux grandes voies en partie souterraines, l'une passant sous la colline de la Croix-Rousse, l'autre sous la colline de Fourvière ${ }^{29}$.

28 Ver detalhes sobre os membros em: FRIOUX, S. Prévoir la ville du futur: "l'avenir en plan". In: PRIVAT-SAVIGNY, Maria-Anne (Dir.). Lyon, centre du monde! L'exposition internationale urbaine de I9I4. Lyon: Musées Gadagne, 20I3, p.I8I-I85.

29 CHALUMEAU, C. Les voies de circonvolution autour des villes et les tunnels urbains. L'urbanisme, 5 e année, $\mathrm{n}$. 43, mars-avril I936, p. I57-I65. Ver citação completa em: < http://www.archives-lyon.fr/static/archives/contenu/ old/fonds/plan-g/p27.htm\#2>. 


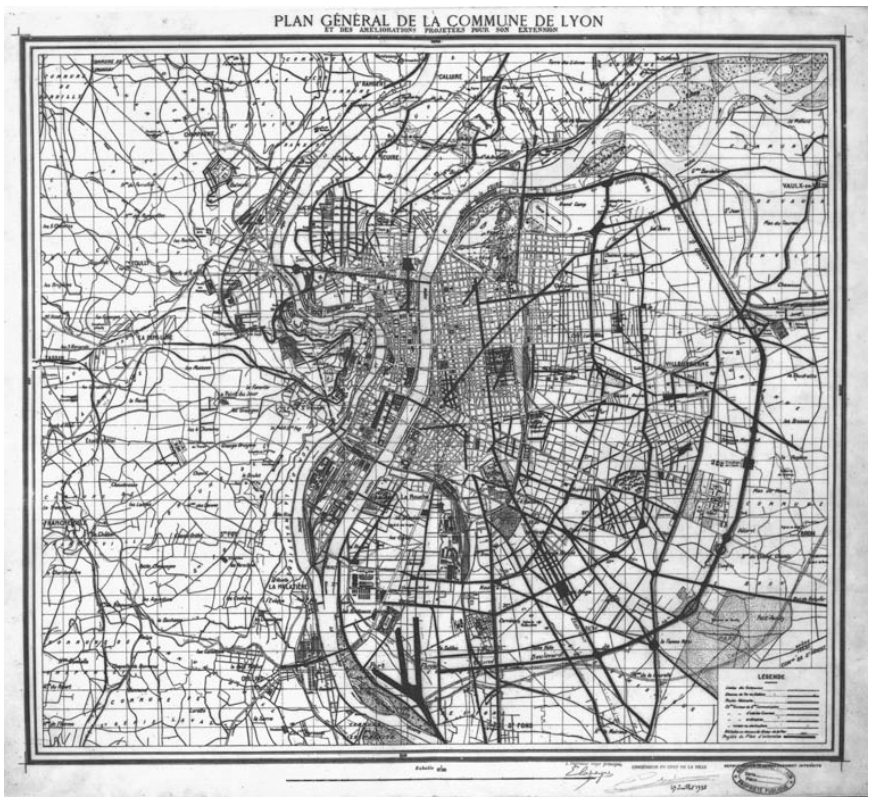

(A)

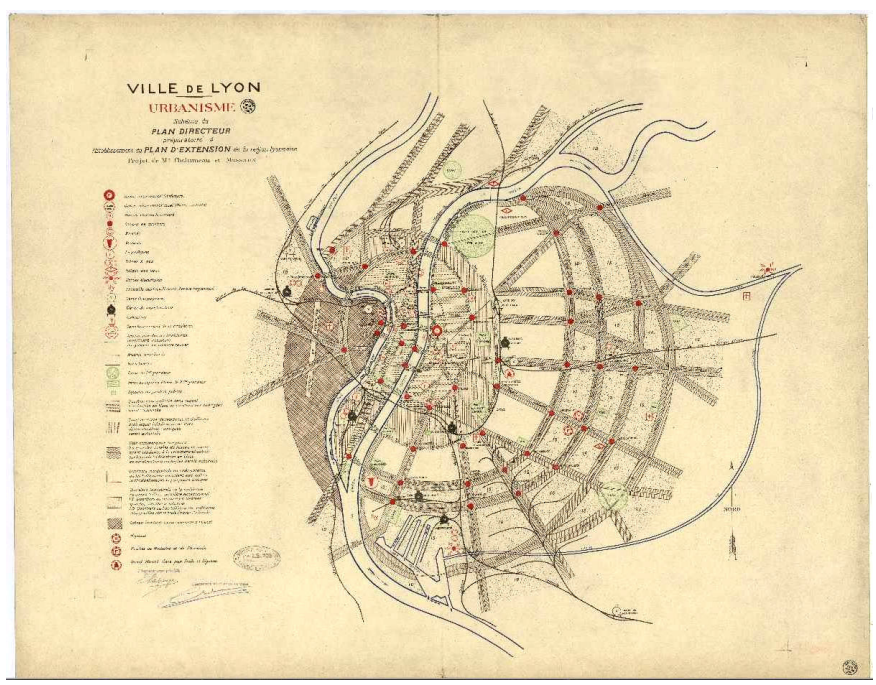

(B)

Figura ro - Planos feitos em vista do que se tornará o Plano Chalumeau insistindo em meios de circulação na cidade, o projeto parte do espaço do concreto para a abstração. Nesses mapas, a zona leste do Rhône é privilegiada como zona de expansão. AML I54I Wp I57/I³0 (figura A); AML 2So933 (figura B)

Na grande série de mapas produzidos em relação a esse plano de circulação, passa-se progressivamente da realidade concreta da cidade (com esboços desenhados sobre os mapas de base do Serviço Viário Municipal), até “croquis” que extrapolam os

30 FORMA URBIS, op. cit., Planche 27. 
detalhes do espaço efetivamente construído, para manter apenas as principais linhas ao redor de um ideal geométrico circular. C. Chalumeau indica que essa visão de uma nova cidade ligada a uma rede maior começa a ser pensada em I9I4, quando Lyon se propõe como uma das capitais do pensamento na exposição urbana internacional dedicada à "cidade moderna", mas é possível encontrar raízes mais distantes para esses projetos em outras representações cartográficas anteriores, onde os interesses econômicos estão bem visíveis. O "Plano da cidade de Lyon, especialmente gravado para o álbum ilustrado do Rhône e do Loire”, de I882, mostra uma preocupação de modelização concêntrica a partir do centro da cidade, onde vários círculos partem da praça central Bellecour e criam zonas de $500 \mathrm{~m}$ de distância - no exemplar disponível nos Arquivos Municipais de Lyon, outros círculos manuscritos, também seguindo distâncias de $500 \mathrm{~m}$, partem do Palácio da Bolsa de valores, onde se localiza a Câmara do Comércio e da Indústria de Lyon (Mapa AML 3SoI28 ${ }^{3 \mathrm{I}}$ ). Os representantes da vida econômica de Lyon que integram a comissão extramunicipal de I9I2 aparecem também em uma série de mapas promocionais ${ }^{32}$ da cidade, seja na forma de quadros publicitários ao redor do mapa apresentado no centro, seja em mapas temáticos, como o mapa sobre o desenvolvimento industrial de I932 (AML 2So456). A maioria desses mapas com referências à economia parece destacar uma cidade que vê, na incorporação do espaço vizinho, uma oportunidade de crescimento que poderia compensar uma certa perda de dinamismo da cidade-centro.

Os documentos associados ao Plano de Chalumeau e sua equipe, realizados, sobretudo entre I9I9 e I945, na ótica de propor um projeto de "desenvolvimento, embelezamento e expansão da cidade de Lyon”, reiteram uma cidade emoldurada muito além dos limites de Lyon. Esse quadro vai se tornar uma realidade administrativa mais clara em 7 de novembro de I938, quando um decreto determina a criação do Grupo de Planeamento da região de Lyon, capaz de desenvolver um plano de desenvolvimento comum, primeiro para 52, depois 53, mais tarde para 56 municípios, dos quais 45 são do departamento Rhône e II de departamentos vizinhos (6 no Ain e 5 do Isere). A ideia da metropolização, preparada nos mapas e lançada na primeira metade do século XX, vem com o desafio de um desenvolvimento concertado fora dos limites não só da cidade, mas também dos departamentos ${ }^{33}$.

\section{Pistas de PESQUisas Futuras}

As primeiras considerações que podemos fazer depois desta rápida leitura dos mapas do início do século XX em Lyon indicam um ritmo de produção cartográfica

3I É interessante notar que no mapa existente no site da Biblioteca Nacional da França ( $\mathrm{BnF}$ - gallica), a segunda série de círculos concêntricos a partir da Bolsa de Valores não foi desenhada, existindo somente os círculos a partir de Bellecour. Ver: BNF Galicca (<http://gallica.bnf.fr/ark:/22I48/btvIb8459243p〉).

32 Nos AML, ver mapas AML 2SI333 e 2Soo8I dos anos I880, e AML 2S0340, 2So34I, AML 2So345, AML 2So348 da primeira metade do século XX.

33 Em janeiro de 20I5, uma lei cria a "metrópole de Lyon", que se torna um departamento com todas as suas atribuições administrativas, quase um século mais tarde. 
irregular sujeito às vicissitudes políticas dos conflitos mundiais. Ainda assim, alguns momentos importantes se distinguem: se os projetos do século XIX continuam no início do século XX, uma nova dinâmica de produção da cidade e de sua imagem se instala ainda antes da década de I9Io, embora só possa ser realizada totalmente no final da experiência traumática da Primeira Guerra Mundial. A década de 1920 é particularmente prolífica na publicação de novos mapas em diferentes escalas e técnicas, mais ou menos relacionados com uma descrição topográfica detalhada do território os empreendimentos lançados nesse período, em grande medida contribuem para moldar o espaço da cidade mesmo além da segunda guerra mundial. Em mapas marcados pelas ideias de "embelezamento", com especial atenção ao tráfego e organização viária, pode-se citar outras perspectivas de investigação para verificar as ligações entre os diferentes projetos de mapeamento simultâneos e analisar assim:

I. a importância da utilização dos planos de grande escala e as relações entre a produção cartográfica local e nacional;

2. o papel crescente de novas técnicas, como a fotografia aérea, na produção cartográfica local;

3. os intercâmbios entre a produção cartográfica de diferentes grupos: topógrafos, engenheiros, planejadores, urbanistas

Obviamente, a análise detalhada dos conteúdos dos mapas não pode ser feita apenas levando-se em consideração os documentos cartográficos. Sabendo-se que, neste período, ocorreram tentativas de controle dos dados produzidos para reforçar uma imagem positiva da cidade ${ }^{34}$, a confrontação das informações apresentadas nos mapas com outras fontes é mais do que necessária. Isso implica também analisar "os silêncios dos mapas", como mencionado por J. B. Harley ${ }^{35}$, e insistir nas especificidades do mapeamento de Lyon em relação a mapeamentos feitos ao mesmo tempo em outras cidades da França e no mundo quanto aos temas e métodos utilizados.

SOBRE A AUTORA

ENALI DE BIAGGI é maître de Conférences do Département de Géographie et aMénagement du TerritoireUniv. Lyon, Université Jean Moulin Lyon 3, UMR 5600 EVS - CRGA, F-69362

34 Ver como foi tratada a questão problemática dos dados de censos no Rhône no início do século XXem:BIENFAIT, J. La population de Lyon à travers un quart de siècle de recensements douteux (I9II-I936). Revue de géographie de Lyon, Année I968, v. 43, n. I, I968, p. 63-94.

35 HARLEY, B. Maps, knowledge and power. In: COSGROVE, D.; DANIELS, S. The iconography of landscape: essays on the symbolic representation, design and use of past environments. Cambridge: Cambridge University Press, I988, p. 277-3I2. 


\section{REFERÊNCIAS BIBLIOGRÁFICAS}

BARBER, P. London, a history in maps. London: The London topographical society, 2012.

BIENFAIT, J. La population de Lyon à travers un quart de siècle de recensements douteux (I9II-I936). Revue de géographie de Lyon, Année I968, v. 43, n. I, I968, p. 63-94.

CHINAL M. Le grand plan parcellaire ou de détails de la ville de Lyon, I860-I970: la contribution des géomètres privés. Forma urbis, les plans généraux de Lyon, XVIe-XXe siècles. Lyon: Archives municipales (Les Dossiers des Archives Municipales n. IO), I997, p. I2I-I34.

FORMA URBIS, les plans généraux de Lyon XVIe-XXe siècles. Lyon: Archives Municipales. Les dossiers des Archives Municipales, Archives municipales, ze édition revue, corrigée et augmentée, I999.

FRIOUX, S. Prévoir la ville du futur: "l’avenir en plan”. In: PRIVAT-SAVIGNY, Maria-Anne (Dir.). Lyon, centre du monde! L'exposition internationale urbaine de I9I4. Lyon: Musées Gadagne, 20I3, p.I8I-I85.

GAUTHIEZ, B. Lyon en I824-32: un plan de la ville sous forme vecteur d'après le cadastre ancien. Géocarrefour [En ligne], v. 83/I, 2008, mis en ligne le I6 février 20I5, consulté le 28 mars 20I6. Disponível em: 〈http://geocarrefour.revues.org/4542〉. Acesso em: 28 mar. 20I6. DOI: I0.4000/geocarrefour.4542. . La transformation de Lyon et Paris au Second-Empire: le projet du ministre de l'Intérieur De Persigny, les exécutants Haussmann et Vaïsse. In: CASAMENTO, Aldo (Dir.). Fondazioni urbane europee dal medioevo al Novecento. Rome: Edizioni Kappa, 20I2, p. 323-344.

HARLEY, B. Maps, knowledge and power. In: COSGROVE, D.; DANIELS, S. The iconography of landscape: essays on the symbolic representation, design and use of past environments. Cambridge: Cambridge University Press, I988, p. 277-3I2.

HINDLE, B. P. Maps for historians. Chichester: Philimore, I998.

LASCOUMES, P. Gouverner par les cartes. Genèses 3 n. 68, 2007, p. 2-3.

METTEY-BUNEVOD, M. Les fortifications de Lyon dans la deuxième moitié du XIXème siècle (I793-I858). Villeneuve d'Ascq: Presses Universitaires du Septentrion, I999.

MORAES, A. C. R. Geografia histórica do Brasil: cinco ensaios, uma proposta e uma crítica. São Paulo: Annablume, 2009.

PELLETIER, J.; DELFANTE Ch. Atlas historique du Grand Lyon. Seysinnet-Pariset: Xavier Lejeune- Libris, 2004 .

SCHULER, C. J. La ville: la cartographie urbaine de l'Antiquité au XXe siècle. Paris: Place des Victoires, $200 I$. SEYMOUR, W. A. (Ed.). A history of the ordnance survey. Folkestones WM Dawson \& Sons, I980. Disponível em: 〈https://www.ordnancesurvey.co.uk/docs/ebooks/history-ordnance-survey.pdf $>$. Acesso em: 20 jun. 2016.

SOUCHON, C. Philibert Vasserot et les Atlas des quartiers de Paris. CFC, n. I7I, mars 2002, p. 37-4I. Disponível em: 〈http://www.lecfc.fr/new/articles/I7I-article-4.pdf 〉. Acesso em: 20 jun. 2016.

VANARIO, Maurice. Lyon, du XVe siècle à nos jours : l'évolution de la ville à travers les principaux plans. Forma urbis, les plans généraux de Lyon, XVIe-XXe siècles. Lyon: Archives Municipales (Les Dossiers des Archives Municipales n. I0), I997. Disponível em: <http://www.archives-lyon.fr/static/archives/ contenu/sommaires/forma_urbis.html >. Acesso em: 20 jun. 2016. 